\title{
Fine-scale genetic population structure of loggerhead turtles in the Northwest Pacific
}

\author{
Y. Matsuzawa, N. Kamezaki, T. Ishihara, K. Omuta, H. Takeshita, K. Goto, T. Arata, \\ H. Honda, K. Kameda, Y. Kashima, M. Kayo, I. Kawazu, J. Kodama, Y. Kumazawa, \\ K. Kuroyanagi, K. Mizobuchi, K. Mizuno, K. Oki, K. K. Watanabe, A. Yamamoto, \\ Y. Yamashita, T. Yamato, T. Hamabata, A. Ishizaki, P. H. Dutton*
}

For list of author affiliations, see Appendix

\begin{abstract}
Effective conservation of globally distributed marine species relies on identification of demographically independent populations to ensure that management actions are directed at the appropriate scale. This identification is particularly challenging for species with complex life histories when local breeding populations have not been adequately sampled. We used mtDNA to analyze the population structure of loggerhead turtles from a total of 555 samples collected from 12 nesting sites in Japan in the Northwest Pacific, including previously unsampled rookeries in the Ryukyu Archipelago, for a comprehensive coverage of the nesting distribution. We identified a total of 9 haplotypes based on $820 \mathrm{bp}$ of the mtDNA control region, including 5 variants of a single previously described $380 \mathrm{bp}$ haplotype. We discovered that 1 haplotype (CcP1.1) previously rare in the North Pacific is common in the Ryukyu Archipelago. Based on analysis of haplotype frequencies, we found significant differentiation among regionally grouped nesting populations (analysis of molecular variance $\mathrm{p}<0.0001, \mathrm{df}=8$; pairwise $F_{\mathrm{ST}}$ ranging from 0.033 to 0.145 ). Our results provide evidence to support the recognition of 3 management units (MU) within the NW Pacific Regional Management Unit (RMU). These include (1) the Ryukyu MU that includes Okinawa, Okinoerabu and Amami, (2) Yakushima Island MU and (3) a Mainland MU that includes Bousou, Enshu-nada, Shikoku, Kii and Eastern Kyushu. These new data from Japan will provide important baseline data for global genetic stock assessments and contribute to our understanding of the population structure, ecology and life history of this migratory marine species in the northern Pacific.
\end{abstract}

KEY WORDS: Mitochondrial DNA · Management units · Population differentiation · Caretta caretta

\section{INTRODUCTION}

Identifying the geographic range of demographically independent populations is important for conservation and management of endangered species, and yet this task can often be challenging given the lack of any unifying set of criteria to define population boundaries, particularly for globally distributed marine species with complex life histories (Waples \& Gaggiotti 2006, Taylor et al. 2010). Sea turtles, which exhibit natal philopatry, tend to have reproductively

${ }^{*}$ Corresponding author: peter.dutton@noaa.gov isolated nesting populations (or rookeries) characterized by differences in composition of matrilineal genetic lineages that are maintained by recruitment of nesting females to their natal beaches (Bowen \& Karl 2007, Jensen et al. 2013). Maternally inherited mitochondrial (mt) DNA markers are useful for studying the stock structure of sea turtles. Management units (MUs) are defined as rookeries (or groups of rookeries) with significant differences in mtDNA haplotype frequencies (Moritz 1994), and these populations are considered to be demographically iso-

() The authors 2016. Open Access under Creative Commons by Attribution Licence. Use, distribution and reproduction are unrestricted. Authors and original publication must be credited. 
lated with respect to female natal recruitment. Since male-mediated nuclear gene flow can occur between MUs defined by mtDNA, it is preferable to use multiple genetic markers to obtain a holistic characterization of population structure (Bowen et al. 2005, Palsbøll et al. 2007). However, in the absence of nuclear data, mtDNA analysis is adequate for defining rookeries as independent nesting populations because female dispersal and recruitment is what shapes rookeries demographically, regardless of the level of male-mediated gene flow. Rookery mtDNA haplotype frequencies are also important for providing baseline data to inform mixed stock analyses, which are used to estimate nesting population origins of foraging turtles (Bolker et al. 2007, Jensen et al. 2013).

For loggerhead turtles, at the global level, 9 regionally significant nesting population aggregations have been recognized as Regional Management Units (RMUs) based on genetic, demographic, geographic and oceanographic considerations: (1) Northwest Atlantic Ocean, (2) Southwest Atlantic Ocean, (3) Northeast Atlantic Ocean, (4) Mediterranean Sea, (5) Southwest Indian Ocean, (6) Northwest Indian Ocean, (7) Southeast Indian Ocean, (8) North Pacific Ocean and (9) South Pacific Ocean, with a tenth putative RMU proposed for the Northeast Indian Ocean for which genetic and biological data are lacking (Wallace et al. 2010). A recent study based on a 380 and 800 base pair (bp) fragment of the mitochondrial control region has demonstrated genetic partitioning within the Atlantic, Mediterranean and Southwest Indian Ocean RMUs (Shamblin et al. 2014). While the mtDNA control region has been a useful marker for detecting stock structure, previous studies have shown that common and widespread haplotypes make it harder to detect fine-scale structure for many marine turtle species (Dutton et al. 1999, Dethmers et al. 2006, Jensen et al. 2013). Longer sequences might have additional variation to help resolve those common haplotypes and provide increased resolution to stock structure (Shamblin et al. 2012a, 2014, LeRoux et al. 2012, Dutton et al. 2013, Jensen et al. 2013).

Genetic stock assessments for loggerheads in the North Pacific have been based on published data for Japan from Hatase at al. (2002a). Recently, the development of new primers has allowed production of additional mtDNA sequence data that have uncovered additional genetic variation among Pacific loggerheads (LeRoux et al. 2008). However, the Japanese nesting populations have not been analyzed with these new tools, so current stock assignments of loggerheads encountered as bycatch in fisheries and estimates of stock composition of foraging aggrega- tions of loggerheads are based on the limited data of Bowen et al. (1995), Hatase et al. (2002a) and Nobetsu et al. (2004). Furthermore, Hatase et al. (2002a) suggested that there was sub-structuring among nesting populations in Japan, which implies that risk factors could impact rookeries in Japan differently, depending on the status of each stock. The evidence presented by Hatase et al. (2002a) for substructuring was weak, due to small sample sizes and low genetic variation in the $384 \mathrm{bp}$ sequence data that were used (Dutton 2007). More recently Watanabe et al. (2011) reanalyzed the data from Hatase et al. (2002a) incorporating 384 bp sequence data from 2 additional nesting sites and found additional evidence of sub-structuring among 5 nesting sites. However, there is extensive loggerhead nesting throughout the Ryukyu Archipelago (Nansei-Shoto) in the southern region of Japan (Kamezaki et al. 2003, Kamezaki 2012) that has not been included in previous genetic surveys. This region represents the southernmost portion of the nesting distribution of loggerheads in the Northwest Pacific.

In this study, we use mtDNA markers to identify the stock structure of loggerheads nesting in the Northwest Pacific. We build on previous work by (1) reanalyzing available samples using $\sim 800$ bp sequences, (2) substantially increasing the sample size for previously analyzed rookeries and (3) including samples from previously unsampled rookeries in the Ryukyu Archipelago for a comprehensive coverage of the nesting distribution. Finally, we consider implications of our findings for conservation of this threatened species.

\section{MATERIALS AND METHODS}

\section{Sample collection}

A total of 555 samples were collected from 12 locations in Japan representing the main loggerhead turtle nesting sites (Fig. 1). Samples consisted of skin plugs from female loggerheads collected from tag punches obtained while applying flipper tags to identify nesting turtles, or dead hatchlings or embryos salvaged from nests that had emerged. Care was taken to avoid duplicate sampling of nests laid by the same female by only sampling unknown nests that were laid within a $10 \mathrm{~d}$ window. Tissue samples were preserved in a concentrated urea buffer (TNESUrea: 6 or $8 \mathrm{M}$ urea; $10 \mathrm{mM}$ Tris-HCl, $\mathrm{pH} 7.5 ; 125 \mathrm{mM}$ $\mathrm{NaCl} ; 10$ mM EDTA; $1 \%$ SDS; Asahida et al. 1996) or $99 \%$ ethanol at room temperature. 


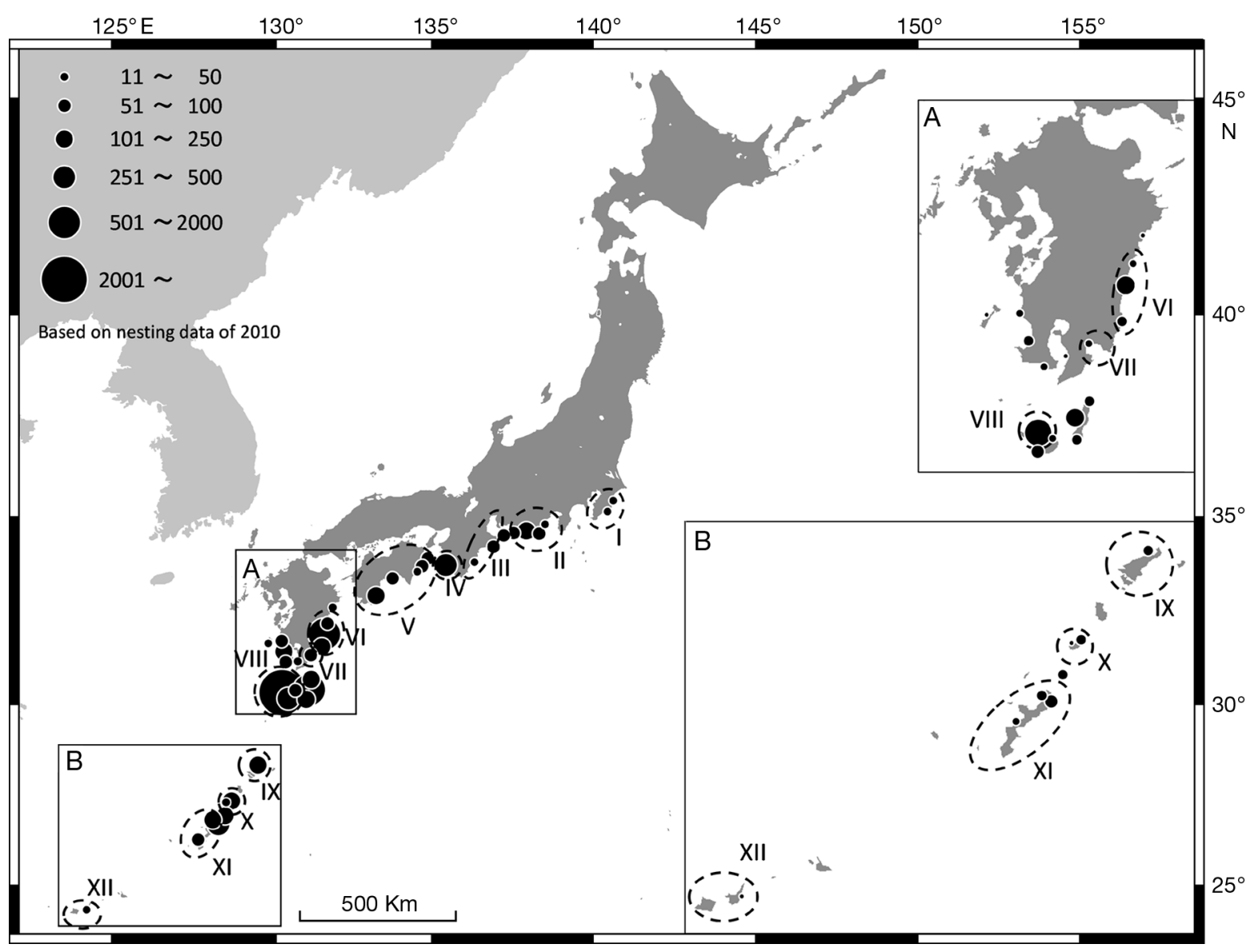

Fig. 1. Nesting and sampling sites of loggerhead turtles Caretta caretta in the Northwest Pacific. Insets show details for (A) Eastern Kyushu and Yakushima and (B) the Ryukyu Archipelago. Black dots show nesting sites (>10 nests) and the relative rookery size (number nests per year) based on 2010 data compiled by the Sea Turtle Association of Japan. Roman numerals and dashed circles indicate the areas in this study, I: Bousou (Chiba, n = 10), II: Enshu-nada (Shizuoka, n = 38), III: Kii (Ise Bay, $\mathrm{n}=11$ ), IV: Kii (Minabe, $\mathrm{n}=101$ ), V: Shikoku (Shikoku, $\mathrm{n}=48$ ), VI: Eastern Kyushu (Miyazaki, $\mathrm{n}=61$ ), VII: Eastern Kyushu (Shibushi Bay, $\mathrm{n}=25$ ), VIII: Yakushima (Yakushima, $\mathrm{n}=108$ ), IX: Ryukyu Archipelago (Amami, $\mathrm{n}=53$ ), X: Ryukyu Archipelago (Okinoerabu, $\mathrm{n}=24$ ), XI: Ryukyu Archipelago (Okinawa Islands, $\mathrm{n}=70$ ), XII: Ryukyu Archipelago (Yaeyama, $\mathrm{n}=6$ )

\section{Laboratory analysis}

Samples were processed and sequenced by a genetic service laboratory, Leave a Nest Co., in Tokyo, Japan, and Akita Prefectural University Biotechnology Center, in Akita, Japan, and Laboratory of Systematic Zoology, Kyoto University, Kyoto, Japan. Primers LCM-15382 and H950g (Abreu-Grobois et al. 2006) were used to generate approximately $820 \mathrm{bp}$ of mtDNA sequence.

\section{Statistical analysis}

We assigned haplotypes by comparing aligned sequences against a local reference library of 800 bp haplotype sequences using Geneious Pro 6.0.2 (Drummond et al. 2011) as well as searching the database on GenBank (www.ncbi.nlm.nih.gov). We standardized nomenclature of haplotypes based on these $\sim 800 \mathrm{bp}$ alignments, assigning the $\mathrm{CcP}$ prefix to numerically sequential names based on the original 384 bp alignments (Bowen et al. 1995, LeRoux et al. 2008) with a sequential numeric suffix to indicate a variant resulting from polymorphism in the additional $386 \mathrm{bp}$ region flanking the old shorter sequence (e.g. CcP2.1, CcP2.2 etc.). Unique sequences were then aligned with the ClustalW algorithm implemented in Geneious Pro 6.0.2 (Drummond et al. 2011). The alignment of each mtDNA segment was checked and edited by eye separately. Haplotype (h) and nucleotide $(\pi)$ diversity were calculated for each rookery using Arlequin v3.5.1.2 (Excoffier \& Lischer 2010). Haplotype diversity was estimated based on Nei (1987), and nucleotide diversity was calculated assuming the model of Tamura \& Nei (1993). We con- 
structed a minimum spanning network (Bandelt et al. 1999) using PopArt v1.7 (http://popart.otago.ac.nz) to illustrate the relationships between haplotypes.

Haplotype diversity $(h)$ analysis, pairwise $F_{\text {ST }}$ comparisons, pairwise exact tests of population differentiation and genetic distance-based analysis of molecular variance (AMOVA) were conducted using the software Arlequin v3.5.1.2 (Excoffier \& Lischer 2010). Significance values for AMOVA were obtained from 10000 permutations. Structure was examined using frequency-based AMOVA, frequency-based pairwise $F_{\mathrm{ST}}$ comparisons and exact tests of population differentiation with $\mathrm{p}$-values $<0.05$ considered significant. Exact tests of population differentiation were conducted with 100000 permutations and 10000 dememorization steps (Raymond \& Rousset 1995). We performed a Mantel test (Mantel 1967) to evaluate the relationship between geographic and genetic $\left(F_{\mathrm{ST}}\right)$ distances in order to test for isolation by distance. Geographic distances $(\mathrm{km})$ were transformed using natural logs, while frequency-based $F_{\mathrm{ST}}$ values were standardized using $F_{\mathrm{ST}} /\left(1-F_{\mathrm{ST}}\right)$ and run in Arlequin using 10000 permutations.

\section{RESULTS}

We identified a total of 9 haplotypes based on the $820 \mathrm{bp}$ sequences, including 5 variants of the previously described 380 bp haplotype 'B' (CcP2) and 2 variants of Haplotype 'C' (CcP3) (Bowen et al. 1995) (Table 1; GenBank ID AB830477-482, AB831106107 and AB842487-88, respectively). Both $\mathrm{CcP}_{\mathrm{C}} 1$ and $\mathrm{CcP} 3$ were relatively distinct from each other and the CcP2 haplogroup (Fig. 2). In the absence of significant differentiation based on initial pairwise tests (not shown), data from adjacent nesting sites of Ise Bay and Minabe were combined to represent a single population for Kii, and data from Miyazaki and Shibushi were combined to represent Eastern Kyushu. Subsequent stock structure analysis was performed using these combined data for turtles nesting in a total of 9 different areas (Table 1). Data from Yaeyama were not included in further analysis due to the small sample size and the uncertainty over whether they are representative of the relative nesting abundance for that distant island.

There was a latitudinal shift in haplotype frequencies, with CcP1.1 relatively common at the southern nesting sites and rare or absent at the northern nesting sites (Table 1). Haplotype diversity ranged from 0.44 to 0.78 , and nucleotide diversity averaged 0.003 (Table 2). Results of the Mantel tests revealed a significant positive relationship between geographical and genetic distances $(r=0.261 ; \mathrm{p}<0.05)$. The AMOVA indicated significant structuring within our study area $(\mathrm{p}<0.0001$, df $=8)$. The pairwise tests indicated the following groupings based on consistent lack of differentiation: (1) Bousou + Enshu-nada + Shikoku + Eastern Kyushu; (2) Kii; (3) Yakushima

Table 1. Frequencies of mtDNA haplotypes for loggerhead turtles Caretta caretta sampled at 12 Northwest Pacific nesting sites based on 820 bp. Equivalent haplotypes (A, B and C) published for shorter 384 bp sequences (Bowen et al. 1995, Hatase et al. 2002a) are shown. Totals for regions are shown in bold. Roman numerals correspond to nesting sites indicated in Fig. 1. Ryukyu total does not include numbers from Yaeyama

\begin{tabular}{|c|c|c|c|c|c|c|c|c|c|}
\hline \multirow[t]{2}{*}{ Location } & \multirow{2}{*}{$\begin{array}{c}(\mathrm{A}) \\
\text { CcP1.1 }\end{array}$} & \multicolumn{5}{|c|}{$\longrightarrow \mathrm{CcP} 2(\mathrm{~B}) \longrightarrow$} & \multicolumn{2}{|c|}{$-\mathrm{CcP} 3(\mathrm{C})-$} & \multirow[t]{2}{*}{ Total } \\
\hline & & $\mathrm{CcP} 2.1$ & $\mathrm{CcP} 2.2$ & $\mathrm{CcP} 2.3$ & $\mathrm{CcP} 2.4$ & $\mathrm{CcP} 2.5$ & $\mathrm{CcP} 3.1$ & CcP3.2 & \\
\hline Bousou & - & 4 & 2 & 1 & - & - & 3 & - & 10 \\
\hline Chiba (I) & - & 4 & 2 & 1 & - & - & 3 & - & 10 \\
\hline Enshu-nada & - & 20 & 5 & 3 & - & - & 9 & 1 & 38 \\
\hline Shizuoka (II) & - & 20 & 5 & 3 & - & - & 9 & 1 & 38 \\
\hline Kii & - & 78 & 10 & 16 & 1 & - & 5 & 2 & 112 \\
\hline Ise Bay (III) & - & 4 & 1 & 3 & - & - & 3 & - & 11 \\
\hline Minabe (IV) & - & 74 & 9 & 13 & 1 & - & 2 & 2 & 101 \\
\hline Shikoku (V) & - & 28 & 7 & 13 & - & - & 7 & - & 55 \\
\hline Eastern Kyushu & - & 55 & 5 & 11 & - & - & 15 & - & 86 \\
\hline Miyazaki (VI) & - & 37 & 5 & 9 & - & - & 10 & - & 61 \\
\hline Shibushi Bay (VII) & - & 18 & - & 2 & - & - & 5 & - & 25 \\
\hline Yakushima (VIII) & 4 & 78 & 1 & 3 & - & - & 22 & - & 10 \\
\hline Ryukyu Archipelago & 34 & 62 & - & 30 & - & 1 & 20 & - & 147 \\
\hline Amami (IX) & 6 & 23 & - & 17 & - & 1 & 6 & - & 53 \\
\hline Okinoerabu (X) & 6 & 11 & - & 4 & - & - & 3 & - & 24 \\
\hline Okinawa Island \& Zamami (XI) & 22 & 28 & - & 9 & - & - & 11 & - & 70 \\
\hline Yaeyama (XII) & 2 & 2 & - & - & - & - & 2 & - & 6 \\
\hline
\end{tabular}




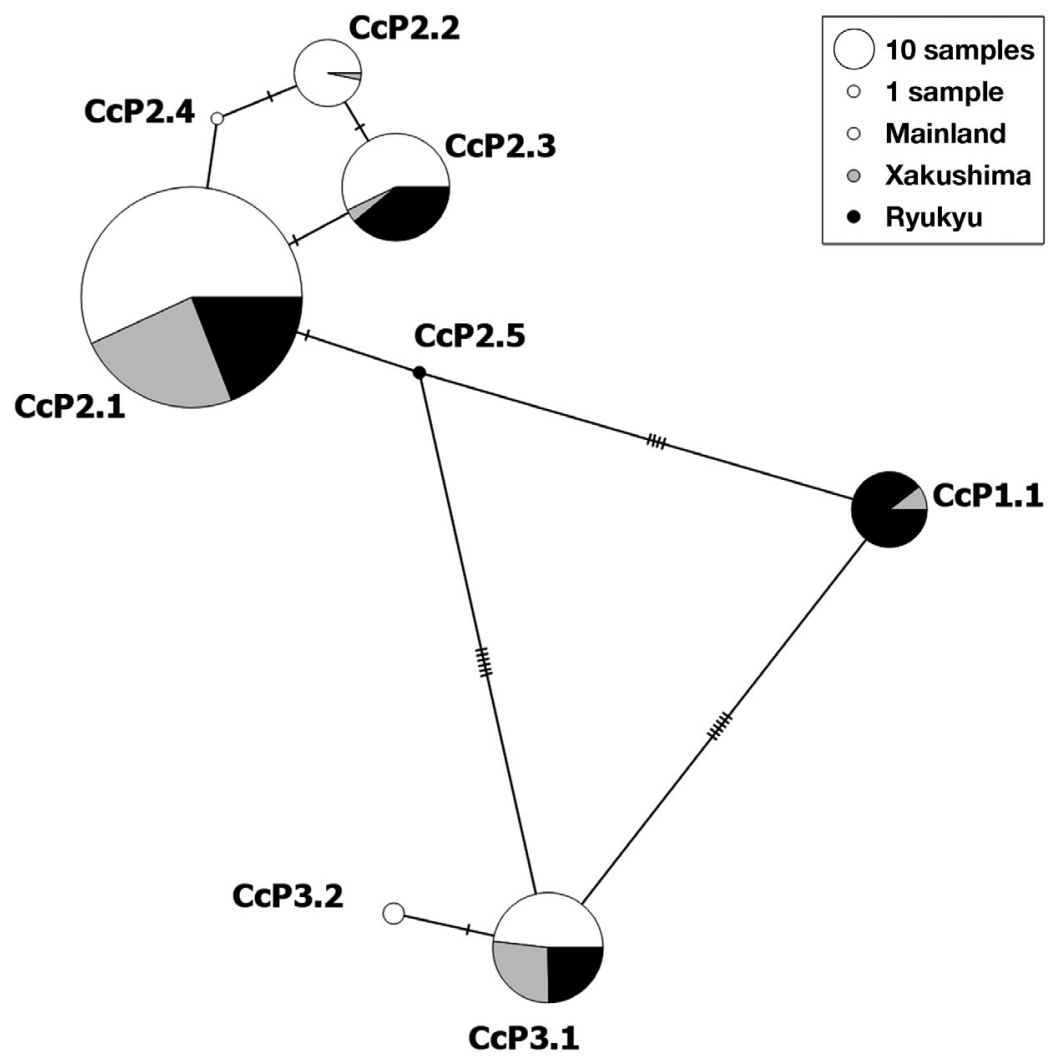

Fig. 2. Most parsimonious minimum spanning network of the $820 \mathrm{bp}$ Japanese loggerhead haplotypes. Number of mutations between haplotypes is illustrated by dashes in connecting lines. The size of the circles represents haplotype frequency in the overall sample set, and proportion of each haplotype is indicated for each of the 3 Japanese loggerhead management units (MUs) identified in our study

Table 2. Genetic diversity parameters for the 11 loggerhead rookeries in the Northwest Pacific based on 820 bp mtDNA control region. The table shows sample size $(n)$, number of haplotypes $(H)$, nucleotide $(\pi)$ and haplotype (h) diversity and their standard deviation (SD). Results for the 7 regions (see Fig. 1) are shown in bold. Yaeyama is not included due to the small sample size

\begin{tabular}{|lrccccc|}
\hline Location & $\mathrm{n}$ & $\mathrm{H}$ & $\pi$ & $\mathrm{SD}$ & $h$ & $\mathrm{SD}$ \\
\hline Bousou & $\mathbf{1 0}$ & 4 & 0.00486 & 0.00299 & 0.7778 & 0.0907 \\
Enshu-nada & $\mathbf{3 8}$ & 5 & 0.00404 & 0.00235 & 0.6600 & 0.0499 \\
Kii & $\mathbf{1 1 2}$ & 6 & 0.00166 & 0.00114 & 0.4886 & 0.0521 \\
$\quad$ Ise Bay & 11 & 4 & 0.00445 & 0.00274 & 0.7818 & 0.0749 \\
Minabe & 101 & 6 & 0.00130 & 0.00095 & 0.4422 & 0.0565 \\
Shikoku & $\mathbf{5 5}$ & 4 & 0.00271 & 0.00168 & 0.6646 & 0.0468 \\
Eastern Kyushu & $\mathbf{8 6}$ & 4 & 0.00292 & 0.00177 & 0.5472 & 0.0524 \\
$\quad$ Miyazaki & 61 & 4 & 0.00293 & 0.00178 & 0.5863 & 0.0591 \\
$\quad$ Shibushi Bay & 25 & 3 & 0.00295 & 0.00184 & 0.4533 & 0.1022 \\
Yakushima & $\mathbf{1 0 8}$ & 5 & 0.00315 & 0.00188 & 0.4387 & 0.0495 \\
Ryukyu Archipelago & $\mathbf{1 4 7}$ & 5 & 0.00148 & 0.00107 & 0.7133 & 0.0195 \\
$\quad$ Amami & 53 & 5 & 0.00328 & 0.00196 & 0.6959 & 0.0376 \\
Okinoerabu & 24 & 4 & 0.00410 & 0.00242 & 0.7138 & 0.0613 \\
$\quad$ Okinawa Island \& & 70 & 4 & 0.00439 & 0.00249 & 0.7101 & 0.0266 \\
$\quad$ Zamami & & & & & & \\
\hline \multicolumn{1}{l}{} \\
\hline
\end{tabular}

and (4) Okinawa + Okinoerabu + Amami (Table 3). Although Okinawa and Amami were significantly differentiated ( $p<0.05)$, neither Amami nor Okinawa were distinct from Okinoerabu, a geographic intermediary between the other 2 rookeries.

\section{DISCUSSION}

The southern Japanese rookeries in the Ryukyu Archipelago make up a separate MU that is demographically distinct from the Yakushima Island and mainland nesting populations. The finding that CcP1.1 is common in the Ryukyu Archipelago rookeries is a significant discovery because this haplotype was previously assumed to characterize the South Pacific loggerhead populations nesting in Australia and New Caledonia (Bowen et al. 1995, P. H. Dutton et al. unpubl. data). In Japan, CcP1 was previously reported only at Yakushima, at relatively low frequency (Hatase et al. 2002a, Watanabe et al. 2011). The presence of $\mathrm{CcP} 1.1$ at Yakushima is one reason this site is also clearly differentiated from the northern rookeries; however, the boundaries between the southern Archipelago, Yakushima and the mainland MUs are slightly tenuous. Based on $F_{\mathrm{ST}}$ results, we identified 3 MUs within the NW Pacific RMU, representing a mainland Japan regional MU, the Yakushima Island population and the Ryukyu Archipelago in the southern part of the nesting range. While results indicated that Kii was differentiated from the other rookeries to the south and from Bousou and Enshu-nada in the north, this distinction was tenuous and should be interpreted with caution. The similarity in haplotype frequencies and discrepancy between the $F_{\mathrm{ST}}$ and exact test results of pairwise comparisons between Kii and the other northern and central rookeries lend uncertainty to designation of Kii as a separate MU. Tagging studies show movement of 
Table 3. Pairwise comparisons based on 820 base pair (bp) control region haplotype frequencies for 9 loggerhead turtle nesting populations in Japan. Nesting population locations are shown in Fig. 1. $F_{\text {ST }}$ values are above the diagonal with significant values (without correction for multiple tests): ${ }^{*} p<0.05{ }^{* *} p<0.01$. Pairwise exact test $p$ values are below the diagonal. BOU: Bousou; ENS: Enshu-nada; KII: Kii; SHI: Shikoku; KYU: Eastern Kyushu; YAK: Yakushima; AMA: Amami; OBU: Okinoerabu; OWA: Okinawa Islands

\begin{tabular}{|llllllllll}
\hline & BOU & ENS & KII & SHI & KYU & YAK & AMA & OBU & OWA \\
\hline BOU & & 0.0000 & $0.0989^{*}$ & 0.0110 & 0.0261 & 0.1017 & 0.0367 & 0.0249 & 0.0515 \\
ENS & 0.85430 & & $0.0476^{*}$ & 0.0062 & 0.0027 & $0.0402^{*}$ & $0.0572^{*}$ & 0.0416 & $0.0757^{* *}$ \\
KII & 0.04676 & 0.01115 & & $0.0334^{*}$ & 0.0107 & $0.0403^{* *}$ & $0.0912^{* *}$ & $0.0928^{* *}$ & $0.1450^{* *}$ \\
SHI & 0.40258 & 0.15334 & 0.07197 & & 0.0150 & $0.0853^{* *}$ & 0.0125 & 0.0324 & $0.0781^{* *}$ \\
KYU & 0.16414 & 0.22023 & 0.03424 & 0.13315 & & 0.0115 & $0.0631^{* *}$ & $0.0579^{*}$ & $0.1039^{* *}$ \\
YAK & 0.01300 & 0.00219 & 0.00000 & 0.00000 & 0.00650 & & $0.1389^{* *}$ & $0.1061^{* *}$ & $0.1419^{* *}$ \\
AMA & 0.02435 & 0.00007 & 0.00000 & 0.00254 & 0.00012 & 0.00000 & & 0.0008 & $0.0392^{*}$ \\
OBU & 0.07611 & 0.00403 & 0.00000 & 0.00208 & 0.00032 & 0.00033 & 0.41868 & \\
OWA & 0.00504 & 0.00000 & 0.00000 & 0.00000 & 0.00000 & 0.00000 & 0.00867 & 0.88371 & 0.0000 \\
\hline
\end{tabular}

some individual female loggerheads between nesting sites at Kyushu, Shikoku, Kii and Enshunada, whereas nesting at other sites is extremely rare for females tagged at Yakushima (Watanabe 2006). This pattern is consistent with our genetic findings. In their study based on the shorter 384 bp sequences, Watanabe et al. (2011) also found significant differentiation between Yakushima and Miyazaki (Eastern Kyushu). We were able to split CcP2 and also CcP3 into several new haplotypes based on the longer sequences, providing finer resolution and further reinforcing the significant differentiation between Yakushima and the other rookeries. Haplotype diversities were substantially lower based on shorter sequences (average of 0.039) reported by Watanabe et al. (2011).

Despite the increased resolution of longer sequences, there could be fine-scale demographic substructuring that our mtDNA markers were not able to detect. Dutton et al. (2013) demonstrated that mtDNA did not have sufficient power to detect the weak population structure $\left(F_{\mathrm{ST}}<0.005\right)$ that characterizes proximate nesting populations in the case of leatherbacks, when compared with an array of informative nuclear (microsatellite) markers. A limited study (that did not include the Ryukyu Islands or some of the northern Mainland sites) using 5 microsatellite markers failed to detect significant substructuring within Japan (Watanabe et al. 2011). However, a more comprehensive study with larger numbers of independent loci would help determine whether there is any weak demographic structuring. Additionally, data from tagging studies may provide information in the future on nesting dispersal patterns of females that could be used to better define connectivity (over shorter time scales than genetics) between different nesting sites within these MUs.
Although our study represents a notable expansion of the geographic scope compared to that of previous studies (Hatase et al. 2002a, Watanabe et al. 2011), such that all the major nesting sites were adequately covered, there were still gaps in the nesting range, resulting from our inability to comprehensively sample areas of low-level sporadic nesting. This limitation may have created artificial 'breaks' in the nesting distribution, which is actually almost continuous along the central and northern coasts of Japan (Fig. 1). This may explain the lack of clear structure evident among the central and northern rookeries, and further sampling of some of the under-sampled intermediate sites will be needed to accurately characterize the level of genetic connectivity among rookeries in this region.

Our findings regarding the nesting distribution in Japan are similar to the NW Atlantic, where loggerhead nesting is almost continuous along the US coast, and it is difficult to identify MUs with clear boundaries based on genetic data. Mitochondrial DNA studies show a gradual shift, or 'cline', in haplotype frequencies with extensive haplotype sharing, such that rookeries at the northern and southern portion of the US nesting distribution are significantly differentiated, but intermediate nesting sites are not (Encalada et al. 1998, Shamblin et al. 2011, 2014). Recent advances using expanded analysis of the mitogenome may provide tools for further resolving finescale structure among the Japanese rookeries (Shamblin et al. 2012b).

The general demographic structuring indicated in our study is consistent with geographic and physical features that likely shaped the patterns of reproductive isolation and natal homing. The Ryukyu nesting sites are geographically isolated from the other 2 MUs. There are likely factors other than geographic 
isolation that contribute to the genetic isolation between other MUs. Yakushima Island, while closer to some of the Mainland MU nesting sites, is separated by a channel strongly influenced by the Kuroshio Current, which may act as an oceanographic barrier (Fig. 3). The high mountain topography of the island ( 2000 m height) and distinct wide sand beaches along with proximity to the Kuroshio Current may also facilitate natal homing by reproductive females. The visual cues of the mountains and beaches are thought to play a role in supplementing the proven magnetic and olfactory mechanisms that adult sea turtles use for long-range homing to natal nesting beaches (Carr 1984, Lohmann et al. 1999).

It should also be noted that male-mediated gene flow will provide a higher level of genetic connectivity between rookeries than is evident from female mtDNA lineage segregation (Watanabe et al. 2011) and should be considered in the broader conservation genetics context and for a more holistic picture of the genetic connectivity within the NW Pacific loggerhead RMU. However, for the purposes of defining nesting population MUs, our mtDNA results are of primary interest.

The 3 haplogroups illustrated in our study (Fig. 2), correspond to the 3 haplogroups described by Hatase et al. (2002a) with shorter 384 bp sequences. Using a Bayesian molecular clock framework, Shamblin et al. (2014) estimated the deepest bifurcation among

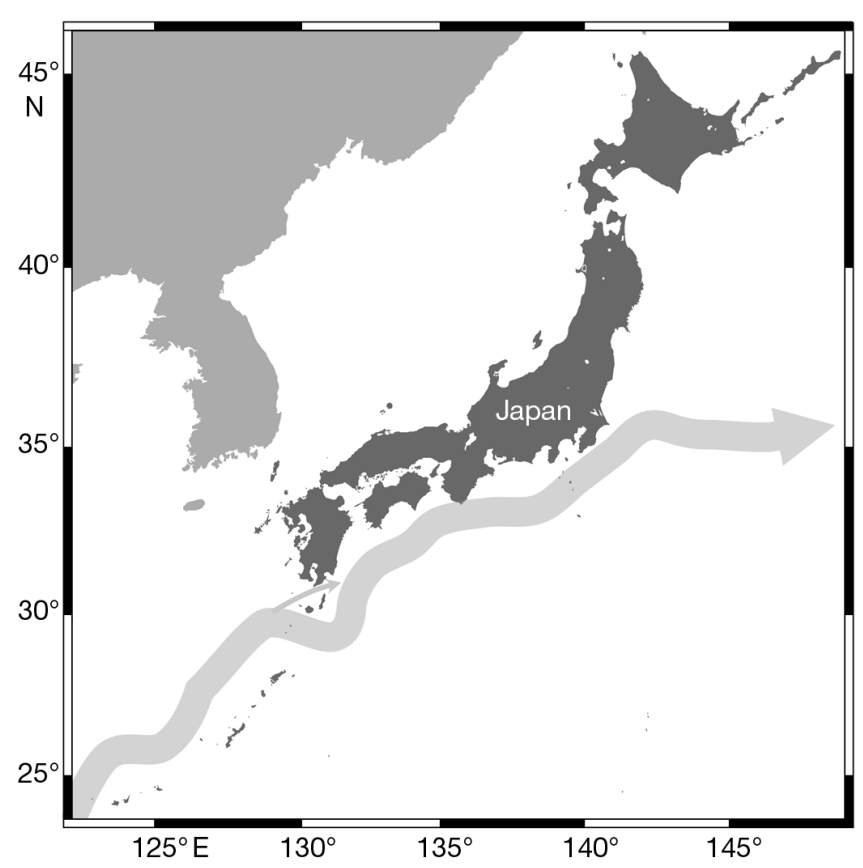

Fig. 3. Kuroshio Current (large arrow) and its branch current (small arrow). These currents may influence nesting site fidelity within management units (MUs)
Pacific loggerhead lineages ( $\mathrm{CcP} 1$ vs. $\mathrm{CcP} 2)$ to be 1.4 million years before present (YBP) $(95 \%$ highest posterior density interval: 0.3 to 2.12 ). Our haplotype network illustrates that the additional diversity detected using longer sequences in our study represents relatively recent accumulation of new mutations within the 3 main mtDNA lineages, primarily $\mathrm{CcP} 2$. The sequence divergence between $\mathrm{CcP} 2.1$ and CcP2.2 (0.002318) provides a reasonable basis to estimate coalescence for this haplogroup to 105000 to 136000 YBP using a molecular clock proposed for a marine turtle mtDNA control region of approximately 1.7 to $2.2 \%$ per million years (Encalada et al. 1996, Dutton et al. 1999). This suggests that the recent evolutionary history of the NW Pacific loggerhead RMU has been shaped by processes occurring at minimum within the last 150000 yr. A more comprehensive analysis with additional data for the South Pacific nesting populations is needed to provide more detailed insights into the evolution, phylogeography and demographic history of loggerheads. Of note here is that the presence of older lineages among all 3 MUs indicate the importance of these Japanese nesting populations for maintaining genetic diversity among loggerheads both in the Pacific and globally.

\section{Conservation implications}

Our results have implications with regard to the appropriate scale of units needed for the effetive conservation of this population in that they provide evidence to support the recognition of at least $3 \mathrm{MUs}$ within the NW Pacific RMU. These are: (1) Ryukyu MU that includes Okinawa, Okinoerabu and Amami, (2) Yakushima Island MU and (3) a Mainland MU that includes Bousou, Enshu-nada, Shikoku and Eastern Kyushu. Due to the uncertainty in the results for Kii with respect to its distinction from the other central/northern rookeries, recognition of Kii as a separate MU is not warranted. However, because it is differentiated from Yakushima and the southern MU, Kii should be provisionally included in the Mainland MU. These MU designations recognize that on a local scale, these groups of rookeries are sufficiently isolated demographically to be treated as independent populations for conservation. Conservation actions on nesting beaches designed to increase hatchling production are expected to result in increased recruitment to the local nesting population as females mature and return to nest at their natal beaches (Dutton et al. 2005). 
The age to maturity of female loggerheads in the North Pacific is $40 \mathrm{yr}$ on average (Ishihara 2011). Until the 1970s, before a ban on harvesting, 80 to $90 \%$ of eggs were poached or legally collected in Yakushima and Miyazaki (Kanno 1976, Uchida 1976, Takeshita 2006). After $>4$ decades of loggerhead conservation, there has been a dramatic increase in nesting, particularly at Yakushima (Omuta 2011, Kamezaki 2012) that is consistent with natal homing expectations for this MU. This increase on Yakushima over the last decade contrasts with the nesting trends observed at a majority of the rookeries within the Mainland MU, which have remained depleted or, at best, slightly increased (Kamezaki 2012, BCJ 2014; see also Yakushima Umigame-kan 2011). However, within the Mainland MU, there is a general lack of consistency between trends at local rookeries. The nesting trend at Miyazaki (Eastern Kyushu), which shows a marked increase, differs from that in the other Mainland regions, including Shikoku, Kii and Enshunada, suggesting that the demographic relationships between these local rookeries may be more complex than is apparent from the genetic results and emphasizing the need to further examine finescale structure.

Despite the lack of a detectable genetic signal to differentiate rookeries within the Mainland MU, in practice, nesting sites are managed as separate populations based on geopolitical and legislative factors. Loggerhead nesting populations in Japan are regulated and managed at local scales ranging from government prefectures, municipalities as well as National Parks and Monuments (Matsuzawa \& Kamezaki 2012) that are generally smaller than the MU identified in our study. Along with geography, demography and physical characteristics, these divisions provide a basis for subdividing the Mainland MU into 'recovery units', similar to the approach used to manage loggerhead nesting populations in the Southeast USA. In the absence of clear MU boundaries (based solely on genetic differentiation) between adjacent rookeries along the Atlantic coast of the USA, a combination of geographic distribution of nesting densities, geographic separation and geopolitical boundaries was used to designate 5 recovery units for conservation and management purposes (NMFS and USFWS 2008). Although there are no obvious geographic breaks in the distribution of nesting habitat in the Mainland Japan MU, generally features of beaches and adjacent landscape differ among regions. River plains and long stretch of beaches with fine sand are common in Miyazaki and Enshunada, where females nest sparsely. In contrast,
Kii and Shikoku are characterized by many small pocket beaches with coarse sand along rocky reefs, where females come ashore to nest densely on some beaches (such as Minabe) but not on others. These geomorphic characteristics may separate Kii from Enshunada and other regions.

The Kagoshima prefecture spans 3 different MUs of Mainland, Yakushima and Ryukyu. Although sea turtle conservation in the water in these 3 geographic areas is controlled separately by different regional fisheries management units, conservation on the beach is covered across-the-board by the Kagoshima Prefectural Sea Turtle Conservation Act. These 3 MUs in this prefecture could be assessed and managed separately to avoid neglecting differences in nesting trends and area-specific threats. Conversely, our proposed MUs provide a framework for neighboring local governments and conservation teams within a MU to share information and cooperate for efficient conservation of the appropriate demographic units based on our genetic results.

Decade-long monitoring has revealed that nesting trends differ among regions (Kamezaki 2012, BCJ 2014; see also Yakushima Umigame-kan 2011). Such differences may reflect differences in MU-specific threats and mortalities not only for eggs and hatchlings on the beach but also for turtles in the water. Contrary to threats on the beach (e.g. Matsuzawa et al. 2002, Kudo et al. 2003), little is known about threats in the water (but see Hatase et al. 2002b, Omuta 2011, Ishihara et al. 2014). Threats resulting in higher mortalities should be identified and addressed to ensure recovery of loggerhead stocks in the North Pacific. This study now provides a baseline to reassess MU-specific threats at sea by enabling more informative mixed stock analysis (see, for example, LaCasella et al. 2013).

Acknowledgements. Tissue samples were collected following guidelines authorized under the Act on the Protection of Fisheries Resources, Natural Parks Act, Cultural Assets Preservation Act and Kagoshima Sea Turtle Protection Ordinance, with the great cooperation of Kuroshima Research Station and Keiichi Ebi in Yaeyama Islands; Umima-ru (Shinya Inoue and Asuka Takamatsu), Shigeo Kobayashi, Rumi Payne, Hisashi Inoue, Churagame (Sea Turtle Research Group of University of Ryukyus), Okinawa Churashima Foundation and Kunio Komesu in Okinawa Islands; Yoron-to Co., Ltd., Yoron Town, Okinoerabu Sea Turtle Network, Doren Campsite and Amami Marine Life Research Association in Amami Islands; Yakushima Umigame-kan, Ryoko Masuyama and the Turtle Crew in Osumi Islands; Miyazaki Wild Life Research Group in mainland Kyushu; Shigeru Noichi, Himeji City Aquarium, Hiroki Tanaka and Hiwasa Chelonian Museum in Shikoku; Akashi City, Minabe Sea Turtle Research Group, Sea Turtle Associ- 
ation of Japan, Kameppuri (Sea Turtle Research Group of Mie University), Kenji Kuroyanagi, Minamichita Beachland Aquarium, Omaezaki City, Kingdom of Kamehameha, Ichinomiya Sea Turtle Research Group, Fukashi Moriya, Katori Moriya, Akemi Watabe, and Aqua World Ibaraki Prefectural Oarai Aquarium in Honshu. This study was funded by Western Pacific Regional Fishery Management Council, Keidanren Nature Conservation Fund, Sea Turtle Association of Japan, and NOAA-Southwest Fisheries Science Center. Erin LaCasella provided assistance with data review, and Michael Jensen and Robin LeRoux provided helpful input to earlier drafts of this manuscript.

\section{LITERATURE CITED}

Abreu-Grobois FA, Horrocks J, Formia A, LeRoux R and others (2006) New mtDNA dloop primers which work for a variety of marine turtle species may increase the resolution capacity of mixed stock analyses. In: Frick M, Panagopoulou A, Rees AF, Williams K (compilers) Book of Abstracts. 26th Annu Symp Sea Turtle Biol Conserv. International Sea Turtle Society, Athens, p 179

Asahida T, Kobayashi T, Saitoh K, Nakayama I (1996) Tissue preservation and total DNA extraction from fish stored at ambient temperature using buffers containing high concentration of urea. Fish Sci 62:727-730

> Bandelt H, Forster P, Röhl A (1999) Median-joining networks for inferring intraspecific phylogenies. Mol Biol Evol 16:37-48

BCJ (Biodiversity Center of Japan) (2014) Overview of sea turtle survey (2004-2012) in the Monitoring-Site 1000 project. Ministry of the Environment, Fujiyoshida City, p 55 (in Japanese with English Abstract)

Bolker BM, Okayama T, Bjorndal KA, Bolten AB (2007) Incorporating multiple mixed stocks in mixed stock analysis: 'many-to-many' analyses. Mol Ecol 16: 685-695

Bowen BW, Karl SA (2007) Population genetics and phylogeography of sea turtles. Mol Ecol 16:4886-4907

> Bowen BW, Abreu-Grobois FA, Balazs GH, Kamezaki N, Limpus CJ, Ferl RJ (1995) Trans-Pacific migrations of the loggerhead turtles (Caretta caretta) demonstrated with mitochondrial DNA markers. Proc Natl Acad Sci USA 92:3731-3734

> Bowen BW, Bass AL, Soares LS, Toonen RJ (2005) Conservation implications of complex population structure: lessons from the loggerhead turtle (Caretta caretta). Mol Ecol 14:2389-2402

Carr A (1984) The sea turtle: so excellent a fishe. University of Texas Press, Austin, TX

Dethmers KEM, Broderick D, Moritz C and others (2006) The genetic structure of Australasian green turtles (Chelonia mydas): exploring the geographical scale of genetic exchange. Mol Ecol 15:3931-3946

Drummond AJ, Ashton B, Buxton S and others (2011) Geneious v.5.4. www.geneious.com/

Dutton P (2007) Genetic stock composition of loggerheads (Caretta caretta) encountered in the Hawaii-based longline fishery using mtDNA analysis. In: North Pacific Loggerhead Sea Turtle Expert Workshop, 19-20 December 2007. A report of the Western Pacific Regional Fishery Management Council pursuant to National Oceanic and Atmospheric Administration Award NOAA Grant FNA05NMF4411092, Honolulu, HI, p 17-19
Dutton PH, Bowen BW, Owens DW, Barragan AR, Davis SK (1999) Global phylogeography of the leatherback turtle (Dermochelys coriacea). J Zool (Lond) 248:397-409

Dutton DL, Dutton PH, Chaloupka M, Boulon R (2005) Increase of a Caribbean leatherback turtle Dermochelys coriacea nesting population linked to long-term nest protection. Biol Conserv 126:186-194

> Dutton PH, Roden SE, Stewart KR, LaCasella EL, Tiwari M, Formia A and others (2013) Population stock structure of leatherback turtles (Dermochelys coriacea) in the Atlantic revealed using mtDNA and microsatellite markers. Conserv Genet 14:625-636

- Encalada S, Lahanas P, Bjorndal K, Bolten A, Miyamoto M, Bowen B (1996) Phylogeography and population structure of the Atlantic and Mediterranean green turtle Chelonia mydas: a mitochondrial DNA control region sequence assessment. Mol Ecol 5:473-483

Encalada SE, Bjorndal KA, Bolten AB, Zurita JC, Schroeder BA and others (1998) Population structure of loggerhead turtle (Caretta caretta) nesting populations in the Atlantic and Mediterranean as inferred from mitochondrial DNA control region sequences. Mar Biol 130: 567-575

Excoffier L, Lischer HEL (2010) Arlequin suite v.3.5: a new series of programs to perform population genetics analyses under Linux and Windows. Mol Ecol Resour 10: $564-567$

> Hatase H, Kinoshita M, Bando T, Kamezaki N and others (2002a) Population structure of loggerhead turtles, Caretta caretta, nesting in Japan: bottlenecks on the Pacific population. Mar Biol 141:299-305

Hatase H, Takai N, Matsuzawa Y, Sakamoto W and others (2002b) Size-related differences in feeding habitat use of adult female loggerhead turtles Caretta caretta around Japan determined by stable isotope analyses and satellite telemetry. Mar Ecol Prog Ser 233:273-281

Ishihara T (2011) Life history in maturation process of loggerhead turtles (Caretta caretta) in North Pacific. PhD dissertation, University of Tokyo (in Japanese)

Ishihara T, Kamezaki N, Matsuzawa Y, Ishizaki A (2014) Assessing the status of Japanese coastal fisheries and sea turtle bycatch. Wildl Human Soc 2:23-35 (in Japanese with English Abstract)

Jensen MP, FitzSimmons NN, Dutton PH (2013) Molecular genetics of sea turtles. In: Wyneken J, Lohmann KJ, Musick JA (eds) The biology of sea turtles, Vol 3. CRC Press, Boca Raton, FL, p 153-154

Kamezaki N (2012) Loggerhead turtles in Japan - ecology and conservation. In: Kamezaki N (ed) Natural history of sea turtles in Japan. Tokyo University Press, Tokyo, p 281-301 (in Japanese)

Kamezaki N, Matsuzawa Y, Abe O, Asakawa H and others (2003) Loggerhead turtles nesting in Japan. In: Bolten $A B$, Witherington BE (eds) Loggerhead sea turtles. Smithsonian Books, Washington, DC, p 210-217

Kanno T (1976) Sea turtles in Yakushima Island. Shizenhogo 174:24-26 (in Japanese)

Kudo H, Murakami A, Watanabe S (2003) Effects of sand hardness and human beach use on emergence success of loggerhead sea turtles on Yakushima Island, Japan. Chelonian Conserv Biol 4:695-696

LaCasella EL, Epperly SP, Jensen MP, Stokes L, Dutton PH (2013) Genetic stock composition of loggerhead turtles Caretta caretta bycaught in the pelagic waters of the North Atlantic. Endang Species Res 22:73-84 
LeRoux RA, Pease VL, LaCasella EL, Frey A, Dutton PH (2008) Longer mtDNA sequences uncover additional genetic variation among North Pacific loggerheads. In: Rees AF, Frick M, Panagopoulou A, Williams K (compilers) Proc 27th Ann Symp Sea Turtle Biol Conserv. NOAA Tech Memo NMFS-SEFSC-569, Silver Spring, MD, p 129-130

LeRoux RA, Dutton PH, Abreu-Grobois AF and others (2012) Re-examination of population structure and phylogeography of hawksbill turtles in the wider Caribbean using longer mtDNA sequences. J Hered 103:806-820

Lohmann KJ, Hester JT, Lohmann CMF (1999) Longdistance navigation in sea turtles. Ethol Ecol Evol 11:1-23

Mantel N (1967) The detection of disease clustering and a generalized regression approach. Cancer Res 27: 209-220

Matsuzawa Y, Kamezaki N (2012) Conservation - conserving endangered species. In: Kamezaki N (ed) Natural history of sea turtles in Japan. Tokyo University Press, Tokyo, p 227-254 (in Japanese)

Matsuzawa Y, Sato K, Sakamoto W, Bjorndal KA (2002) Seasonal fluctuations in sand temperture: effects on the incubation period and mortality of loggerhead sea turtle (Caretta caretta) pre-emergent hatchlings in Minabe, Japan. Mar Biol 140:639-646

Moritz C (1994) Defining 'evolutionarily significant units' for conservation. Trends Ecol Evol 9:373-375

Nei M (1987) Molecular evolutionary genetics. Columbia University Press, New York, NY

NMFS (National Marine Fisheries Service) and USFWS (US Fish and Wildlife Service) (2008) Recovery plan for the Northwest Atlantic population of the loggerhead sea turtle (Caretta caretta), 2nd revsn. National Marine Fisheries Service, Silver Spring, MD

Nobetsu T, Minami H, Matsunaga H, Kiyota M, Yokota K (2004) Nesting and post-nesting studies of loggerhead turtles (Caretta caretta) at Omaezaki, Japan. In: Proc 5th SEASTAR2000 Workshop Dec 13-15, 2004. Kyoto University, Kyoto, p 30-33

Omuta K (2011) Conservation project on Yakushima Island: the biggest nesting site in Japan. In: Dutton PH, Squires D, Ahmed M (eds) Conservation of Pacific sea turtles. University of Hawaii Press, Honolulu, HI, p 108-119

Palsbøll PJ, Berube M, Allendorf FW (2007) Identification of management units using population genetic data. Trends Ecol Evol 22:11-16

Raymond M, Rousset F (1995) An exact test for population differentiation. Evolution 49:1280-1283

Shamblin BM, Dodd MG, Bagley DA, Ehrhart LM, Tucker $\mathrm{AD}$ and others (2011) Genetic structure of the southeastern United States loggerhead turtle nesting aggregation: evidence of additional structure within the peninsular Florida recovery unit. Mar Biol 158:571-587
Shamblin BM, Bolten AB, Bjorndal KA, Dutton PH, Nielsen JT and others (2012a) Expanded mitochondrial control region sequences increase resolution of stock structure among North Atlantic loggerhead turtle rookeries. Mar Ecol Prog Ser 469:145-160

Shamblin BM, Bjorndal KA, Bolten AB and others (2012b) Mitogenomic sequences better resolve stock structure of southern Greater Caribbean green turtle rookeries. Mol Ecol 21:2330-2340

Shamblin BM, Bolten AB, Abreu-Grobois FA, Bjorndal KA, Cardona L and others (2014) Geographic patterns of genetic variation in a broadly distributed marine vertebrate: new insights into loggerhead turtle stock structure from expanded mitochondrial DNA sequences. PLoS ONE 9:e85956

Takeshita H (2006) The current status of loggerhead sea turtle rookeries in Miyazaki, Japan. In: Kinan I (ed) Proc Western Pacific Sea Turtle Coop Research and Management Workshop. Vol II: North Pacific loggerhead sea turtles. Western Pacific Regional Fishery Management Council, Honolulu, HI, p 27-29

Tamura K, Nei M (1993) Estimation of the number of nucleotide substitutions in the control region of mitochondrial DNA in humans and chimpanzees. Mol Biol Evol 10: 512-526

Taylor BL, Martien K, Morin P (2010) Identifying units to conserve using genetic data. In: Boyd IL, Bowen WD, Iverson SJ (eds) Marine mammal ecology and conservation - a handbook of techniques. Oxford University Press, Oxford, p 306-344

Uchida I (1976) My impressions of Kanno's article. Shizenhogo 174:26 (in Japanese)

- Wallace BP, DiMatteo AD, Hurley BJ, Finkbeiner EM, Bolten AB and others (2010) Regional management units for marine turtles: a novel framework for prioritizing conservation and research across multiple scales. PLoS ONE 5:e15465

> Waples RS, Gaggiotti O (2006) What is a population? An empirical evaluation of some genetic methods for identifying the number of gene pools and their degree of connectivity. Mol Ecol 15:1419-1439

Watanabe KK (2006) Studies on gene flow and migratory ecology in Japanese loggerhead turtles (Caretta caretta). PhD dissertation, University of Tokyo, Tokyo (in Japanese)

- Watanabe KK, Hatase H, Kinoshita M, Omuta K and others (2011) Population structure of the loggerhead turtle Caretta caretta, a large marine carnivore that exhibits alternative foraging behaviors. Mar Ecol Prog Ser 424:273-283

Yakushima Umigame-kan (2011) Report on sea turtle research in Yakuhshima Island (1985-2009). Yakushima Umigame-kan, Kagoshima, p 101 (in Japanese) 
Appendix. Complete list of author addresses

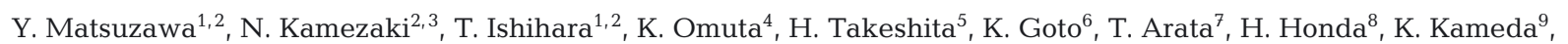
Y. Kashima ${ }^{10}$, M. Kayo ${ }^{1}$, I. Kawazu ${ }^{11}$, J. Kodama ${ }^{5}$, Y. Kumazawa ${ }^{12}$, K. Kuroyanagi ${ }^{13}$, K. Mizobuchi ${ }^{14}$, K. Mizuno $^{15}$, K. Oki ${ }^{15}$, K. K. Watanabe ${ }^{16}$, A. Yamamoto ${ }^{17}$, Y. Yamashita ${ }^{18}$, T. Yamato $^{1}$, T. Hamabata $^{19}$, A. Ishizaki ${ }^{20}$, , P. H. Dutton $^{21, *}$

${ }^{1}$ Sea Turtle Association of Japan, 5-17-18 Nagaomotomati, Hirakata, Osaka 573-0163, Japan

${ }^{2}$ Suma Aqualife Park Kobe, 1-3-5 Wakamiya-cho, Suma, Kobe, Hyogo 654-0049, Japan

${ }^{3}$ Okayama University of Science, 1-1 Ridai-cho, Okayama, Okayama 700-0005, Japan

${ }^{4}$ Yakushima Umigame-Kan, 489-8 Nagata, Yakushima, Kumage-gun, Kagoshima 891-4201, Japan

${ }^{5}$ Miyazaki Wildlife Research Group, 1-5-14 GakuenKihanadaikita, Miyazaki, Miyazaki 889-2152, Japan

${ }^{6}$ Minabe Sea Turtle Research Group, 278 Higashiyoshida, Minabe, Wakayama 645-0001, Japan

${ }^{7}$ Doren Camp Site, 2887-9 Ankyaba, Tatsugo, Oshima-gun, Kagoshima 894-0323

${ }^{8}$ Churagami University of the Ryukyus, 1 Senbaru, Nishihara, Okinawa 903-0213, Japan

${ }^{9}$ Kuroshima Research Institute, Sea Turtle Association of Japan, 136 Kuroshima, Taketomi, Yaeyama, Okinawa 907-1311, Japan

${ }^{10} 193$ Miyanomoto, Mugiura, Mugi, Kaifu-gun, Tokushima 775-0012, Japan

${ }^{11}$ Okinawa Churashima Research Center, 888 Ishikawa, Motobu, Okinawa 905-0206, Japan

${ }^{12} 3302-1$ Higashimorogi, Haruno, Kochi 781-0315, Japan

${ }^{13}$ Minamichita Beachland Aquarium, 428-1 Okuda, Mihama, Chita, Aichi 470-3233, Japan

${ }^{14} 372-4$ Fuwa, Shimanto, Kochi 787-0017, Japan

${ }^{15}$ Amami Marine Life Research Association, 99-1 Hiramatsucho Naze, Amami, Oshima, Kagoshima 894-0045, Japan

${ }^{16}$ National Institute for Land and Infastructure Management, 1 Asahi, Tsukuba, Ibaraki 305-0804, Japan

${ }^{17}$ Kingdom of Kamehameha, 508-3 Hadu, Makinohara, Shizuoka 421-0523, Japan

${ }^{18}$ Okinoerabujima Sea Turtle Network, 952 Furusato, Wadomari, Oshimagun, Kagoshima 891-9111, Japan

${ }^{19}$ Graduate School of Science, Kyoto University, Kitashirakawa-Oiwakecho, Sakyo, Kyoto 606-8502, Japan

${ }^{20}$ Western Pacific Regional Fishery Management Council, 1164 Bishop St 1400, Honolulu, HI 96813, USA

${ }^{21}$ Marine Mammal and Turtle Division, Southwest Fisheries Science Center, National Marine Fisheries Service,

National Oceanic and Atmospheric Administration, 8901 La Jolla Shores Drive, La Jolla, California 92037, USA

Editorial responsibility: Kartik Shanker,

Bangalore, India
Submitted: August 19, 2015; Accepted: January 23, 2016

Proofs received from author(s): March 26, 2016 